\title{
Part 13. Issuing Medical Certificates: How sick do you have to be to actually "Be sick"?
}

\section{INTRODUCTION}

Absenteeism from work as a result of sickness places a tremendous financial burden on the economy of any country. In 2013, the Adcorp index revealed that 3.96 million South Africans were absent from work due to illness as compared with 700000 in 2000. Not only did this result in billions of rand being lost on a yearly basis, but the increasing trend is a major concern for the future. Thus the question arose: "How sick do you have to be... to be sick?" In 1948, The World Health Organization (WHO) defined health in its broader sense as "a state of complete physical, mental, and social well-being and not merely the absence of disease or infirmity." It was initially widely acclaimed for its inclusion of physical, mental and social domains. ${ }^{1}$ However, since then it has been criticized by many because of its lack of operational value, ambiguity, and the problems created by use of the word "complete" in relation to wellbeing. ${ }^{2}$ Strict application of that unmeasurable criterion could categorise most people as unhealthy, or able to declare themselves "unwell" much of the time! It is also counterproductive in that it declares those with chronic conditions and disabilities as ill, and could inhibit people's natural capacity to adapt and cope with physical, emotional and social challenges. ${ }^{2}$

At the same time, sickness has almost as many definitions as there are types of ailments, ranging from being affected by a physical or mental illness, to feeling unwell, poorly, ailing, indisposed, laid up, nauseous, ghoulish, morbid, intensely annoyed or merely bored. It can also

1. Leanne M Sykes: BSc, BDS, MDent (Pros), Dip Res Ethics (Irensa), Dip Forensic Odont. Department of Prosthodontics, University of Pretoria.

2. William G Evans: BDS, Dip Orth. Department of Orthodontics, University of Witwatersrand.

3. Fatima Gani: BDS, MSc(Dent). Department of Prosthodontics, University of Pretoria

4. Portia Nethononda: BSC, BDS, PDD (Clinical). Department of Prosthodontics, University of Pretoria.

Corresponding author

Leanne M Sykes:

Department of Prosthodontics, University of Pretoria.

E-mail: leanne.sykes@up.ac.za be described from different viewpoints as a disease (medical perspective), sickness (society's perspective) or illness (how the patient perceives his/her condition). These concepts represent different aspects of morbidity and need to be considered as separate entities. ${ }^{3}$ How then does a dentist decide when a patient is completely healthy, persevering with slight ailments, mildly sick, or so incapacitated as to warrant a medical certificate that excuses them from work?

\section{LABOUR LAW}

Before considering the legal aspects of sick leave, it is useful to be reminded of specific relevant South African legislature. The Basic Conditions of Employment Act applies to all employers and workers excluding: members of the National Defence Force, National Intelligence Agency, Secret Service, and unpaid charity volunteers. In addition, the regulation of working hours is not applicable to workers in senior management, sales staff who travel and regulate their own working hours, those who work less than 24 hours a month, those who earn above the amount stated in section 6 (3) of the Act, and workers engaged in emergency work. ${ }^{4}$ With regards to sick leave, workers may take the number of days they would normally work in a six-week period as sick leave on full pay over a three-year period. This excludes the first six months when a worker is entitled to only one day of paid sick leave for every 26 days worked. These provisions do not apply to those who work less than 24 hours a month, workers who receive compensation for an occupational injury, and any leave over and above that provided by the Act. ${ }^{4}$ Employers may demand a medical certificate for workers who are absent for more than two consecutive days, or who are absent more than twice in an eight-week period. ${ }^{4}$

\section{HPCSA GUIDELINES ON WHAT SHOULD BE WRITTEN AND HOW}

The HPCSA Booklet 14 sets out guidelines on the keeping of patient records and the issuing of documents. Clinicians are required to keep a record of the date, time and place of every consultation, the assessment of the patient's condition at that visit, and the dates and times that the patient was booked off from work along with the relevant reasons. 
Rule 16 pertains to the issuing of medical certificates. For the certificate to be legally valid it must adhere to certain requirements as laid out in the Basic Conditions of Employment Act. It must be issued by a medical practitioner who must state that based on his/her professional opinion, the employee is unable to perform duties because of the illness. It is not good enough to merely state that the practitioner "saw the patient" or "was informed by the patient", as this does not clearly state that the clinician diagnosed the patient with any specific condition to warrant absence from work ( ${ }^{* *}$ the actual diagnosis does not need to be disclosed in the certificate - see below). The certificate must record: the name, address and qualification of the practitioner; the contact numbers and physical address; the practice registration number; the name of the patient; employment number of the patient (if applicable); date and time of the examination; whether the certificate is being issued as a result of personal observations by the practitioner during an examination, or as the result of information received from the patient, and which is based on acceptable medical grounds; a description of the illness, disorder or malady in layman's words and with the informed consent of the patient; ( ${ }^{* *}$ Note: With the introduction of the Protection of Personal Information Act (POPI) act, and doctor-patient privilege the patient does not have to consent to this information or to a revelation of the diagnosis. In this case the clinician can merely specify that he/she has examined the named patient, and that in his/her opinion based on the examination, the patient is unfit to work for the specified dates and times); whether the patient is totally indisposed for duty or whether able to perform less strenuous duties in the work situation; the exact period of recommended sick leave; the date of issuing the certificate of illness and clear information of their identity. Backdated certificates are acceptable if the practitioner stipulates that in their professional opinion the employee was unable to perform their normal duties during the backdated period.

Rule 15 states that when official documents are issued, including medical certificates, these must be signed by the authorised person followed by his/her initials and surname in printed or bold letters. ${ }^{5}$

[Note: The rules governing the retention of records will not be discussed in this paper as they are clearly stated in Booklet 14 of the HPCSA. ${ }^{5}$ ]

\section{SPECIFIC DENTAL CONSIDERATIONS}

While the legalities surrounding the issuing, format and contents of a medical certificate are clear, the decision on when they are justified and warranted is a far more difficult task. The clinician may be influenced by subjective views, personal opinions, emotional feelings, sentiments, his/her own attitudes towards sickness as well as an appraisal of the circumstances of each patient. In this regard, issues to be considered may include:

\section{Patient socio-economic factors}

- Transport time and costs incurred to get to their appointment.

- Can a person be granted sick leave when they accompany a child / minor / elderly / infirm or other dependant person to their appointment?
Dentist / practice related factors

- Waiting times (may be due to the dentist running late, practices where patients are seen as walk-ins as opposed to those who run on appointments, attendance at government clinics where patients have to arrive early to be put on that day's list).

- Delayed appointments due to unforeseen emergencies with a previous patient.

- Procedures that take longer than anticipated (extraction with complications).

- Can a dentist sign for a family member, colleague, or patient based on a report from that person or some other third party without personally and physically examining the patient? Even when the third party is a colleague or other medical professional?

- What are the dentist's duties to an employer when he/she suspects that a patient is returning for many unnecessary visits and requesting medical certificates to excuse him/her from work on each occasion?

\section{Dentist's value judgements}

- Dentists may have to estimate the degree of pain the patient is experiencing or may experience after the treatment.

- Is sick leave warranted for associated morbidity without actual pain or illness? For example, swelling, malodour, numbness, bruising, or any other conditions that the patient may feel embarrassed about in their work environment.

- Bleeding after a procedure. How much time should be granted away from work for this? It is a question of how much bleeding is normal, when can it be anticipated to stop and how much discomfort it causes the patient.

- Sepsis post-operatively such as a dry socket. Here there would be a cause for retrospective sick leave as well as prospective. When should the dentist have been consulted and how much time is reasonable to be away from work?

- Can a dentist grant sick leave based on a telephonic conversation even if it does follow a scheduled appointment where the patient had been seen or treated? How long after that appointment can the dentist still entertain requests for sick leave without seeing the patient again?

- Should a patient be allowed sick leave for pain following an endodontic procedure, and if so, for how long?

- Is it permissible and reasonable to ask for sick leave when a patient has attended for prophylactic treatment or a routine consultation?

- Can a patient be given sick leave for time spent having cosmetic dentistry such as a bleaching procedure (and the subsequent sensitivity)?

- How does the clinician decide and determine how many days sick leave are justified for different conditions, as pain and morbidity are subjective and unmeasurable. Should it differ for a patient who had a simple extraction, one who had extraction with complications, for a patient who underwent a surgical extraction under local anaesthesia, under conscious sedation or under general anaesthesia? How do you calculate hospital admission times, theatre time, post-operative recovery and subsequent days off from work? 
- How does the dentist determine if a patient is partially incapacitated or fully disabled by his/her dental condition in terms of his/her job requirements?

In many of these situations, the issuing of a medical certificate and number of days decided upon are based on both the professional diagnostic proficiency and experiential discretion of the clinicians as well as the extent of trust between themselves and their patients. However, it may be very difficult to question the legitimacy of a request when it is felt that the patient's condition does not warrant sick leave. It can also be hard to refuse the subtle pressure from those who ask for this. How then do dentists refuse to issue a certificate without compromising those patients who do have a genuine malady, or souring the relationship they have with those whose veracity they have questioned?

A final consideration is that according to the Basic Conditions of Employment Act, sick leave cannot be granted for routine check-ups, examinations, tests, collecting medicines from a pharmacy, and visits to specialist medical practitioners. ${ }^{4}$ Where then does this leave dentistry which is striving to move away from being "treatment based" to focusing on prevention of disease? By not making provision for patients to have regular dental prophylaxis the law is in direct opposition to the WHO aims of Health Promotion. Should the dental fraternity be challenging these rulings?

\section{CONCLUSION}

The final decisions regarding issuing of medical certificates and amount of time requested rests on the discretion and professional opinion of the treating clinician. Considering the diverse range of dental conditions, treatment modalities, levels of patient tolerance and psychosocial factors involved, it is clear that there can be no concrete rules or directives. Each situation and decision needs to be guided by the "reasonable dentist / patient" rule. Perhaps two deciding questions to ask are "Can you justify your decision and the contents of the medical certificate if called upon to do so in a Court of Law?" And "Is it based on legal, professional, social and ethical considerations?" If the answer to both of these is affirmative, the dentist should feel at ease issuing the medical certificate.

\section{References}

1. WHO. WHO Definition of Health. Accessed at: who.int/about/ definition/en/print.html2016.

2. Huber M, Knottnerus JA, Green, L, van der Horst H, Jadad AR, Kromhout D, Smid H. How should we define health? BMJ. 2011;343:4163.

3. Wikman A, Marklund S, Alexanderson K. Illness, sickness and disease absence: an empirical assessment of differences between concepts of ill health. J Epidemiol Com Health. 2005;59:450-4.

4. Labour Do. Basic Guide to Sick Leave. In: Labour Do, editor. South Africa: Accessed at: www.labour.gov.za/acts/basicguides/basic-guide-to-sick-leave; Accessed on: 01-03-2017.

5. HPCSA. Guidelines on the Keeping of Patient Records. Booklet 14, (May 2008. Accessed on: 01-03-2017); Accessed at: http://www.hpcsa.co.za.

6. Fin 24. Sick leave costs SA billions. Accessed on 15-03-2017; Accessed at: www.fin24.com/Economy/Sick-leave-costs-SAbillions-20130910. 